\title{
La falla en la vigilancia de los mecanismos de seguridad en la importación de vehículos y su incidencia en la responsabilidad del Estado
}

The Failure in the Surveillance of the Security Mechanisms in the Importation of Vehicles and its Incidence in the Responsibility of the State

A falha na vigilância dos mecanismos de segurança na importação de veículos e seu impacto sobre a responsabilidade do Estado

\section{William Eugene Ulrich Astaiza ${ }^{1}$}

Recibido: 12 de agosto de 2020 Aprobado: 18 de octubre de 2020

Publicado: 12 de enero de 2021

Cómo citar este artículo: William Eugene Ulrich Astaiza. La falla en la vigilancia de los mecanismos de seguridad en la importación de vehículos y su incidencia en la responsabilidad del Estado. DIXI, vol. 23, $n^{\circ}$. 1, enero-junio 2021, 1-23. DOI: https://doi.org/10.16925/2357-5891.2021.01.08

Artículo de reflexión. https://doi.org/10.16925/2357-5891.2021.01.08

1 Magíster en Derecho Administrativo, Universidad del Cauca. Especialista en Derecho Administrativo Universidad del Cauca. Abogado, Universidad Cooperativa de Colombia. Abogado litigante, investigador independiente.

Correo electrónico: williamulrich8512@gmail.com

ORCID: https://orcid.org/0000-0003-4652-4486 
2 La falla en la vigilancia de los mecanismos de seguridad en la importación de vehículos y su incidencia en la responsabilidad del Estado

\section{Resumen}

Objetivo: determinar la responsabilidad del Estado colombiano a partir de la falla en el servicio por la importación de vehículos que no cumplen con estándares de calidad. Además, se busca establecer que la normatividad vigente en seguridad vehicular propone criterios de distinción que son insostenibles en un Estado Social de Derecho.

Metodología: la metodología utilizada fue la de revisión sistemática de fuentes bibliográficas, jurisprudenciales y legales, y la solicitud mediante peticiones a las entidades correspondientes (MinCyT, Dian, MinTransporte). Una vez analizada y sistematizada la información, se procedió a hacer la interpretación y construcción del presente texto.

Conclusiones: la responsabilidad del Estado se ve comprometida con aquellos vehículos que circulan sin las medidas de seguridad establecidas en la Resolución 3752 de 2015, dado que si bien esta norma no es de carácter retroactivo, sí evidencia que el Estado no está en la capacidad de proteger a todos los colombianos en su vida, honra y bienes, y que es en razón a esto que la falla en las medidas de seguridad en las importaciones ha permitido que vehículos inseguros como taxis tipo sin bodega y sin airbag dual, frenos ABS ni apoyacabezas circulen por las ciudades sin ningún tipo de control a su seguridad.

Palabras clave: importaciones, responsabilidad del Estado, seguridad, teoría del riesgo, vehículos.

\section{Abstract}

Objective: To determine the responsibility of the Colombian State for the failure in service due to the importation of vehicles that do not comply with quality standards. In addition, it seeks to establish that the current regulations on vehicle safety propose criteria of distinction that are unsustainable in a Social State under the rule of law.

Methodology: The methodology used was the systematic review of bibliographic, jurisprudential and legal sources, and the request through petitions to the corresponding entities (MinCyT, Dian, MinTransporte). Once the information was analyzed and systematized, the interpretation and construction of this text was carried out.

Conclusions: The responsibility of the State is compromised with those vehicles that circulate without the safety measures established in Resolution 3752 of 2015, given that although this rule is not retroactive, it does evidence that the State is not able to protect all Colombians in their life, honor and property, and that it is because of this that the failure in the safety measures in imports has allowed unsafe vehicles such as cabs without storage and without dual airbags, ABS brakes or headrests to circulate through the cities without any kind of control to their safety.

Keywords: Imports, state responsibility, safety, risk theory, vehicles.

\section{Resumo}

Objetivo: determinar a responsabilidade do Estado colombiano pelo fracasso do serviço devido à importação de veículos que não cumprem com os padrões de qualidade. Além disso, procura estabelecer que a regulamentação atual sobre segurança veicular propõe critérios de distinção insustentáveis em um Estado Social sob o Estado de Direito.

Metodologia: a metodologia utilizada foi a revisão sistemática de fontes bibliográficas, jurisprudenciais e legais, e a solicitação através de petições às entidades correspondentes (MinCyT, Dian, MinTransporte). Uma vez que as informações foram analisadas e sistematizadas, procedemos à interpretação e construção deste texto. 
Conclusões: a responsabilidade do Estado está comprometida com aqueles veículos que circulam sem as medidas de segurança estabelecidas na Resolução 3752 de 2015, dado que embora esta regra não seja retroativa, ela mostra que o Estado não é capaz de proteger todos os colombianos em sua vida, honra e propriedade, e que é por isso que a falha nas medidas de segurança nas importações permitiu que veículos inseguros como táxis sem porão e sem airbags duplos, freios ABS ou encostos de cabeça circulassem pelas cidades sem nenhum controle para sua segurança.

Palavras-chave: importação, responsabilidade do Estado, segurança, teoria de risco, veículos.

\section{INTRODUCCIÓN}

La responsabilidad del Estado es un tema que no conoce límite, debido a que todos los días aparecen nuevas formas de responsabilidad frente a un ente que siempre está presente y que sin importar si actúa de forma intencional o no, causa daños a quienes administra, y naturalmente este daño, tal y como lo regla la Constitución Política (artículo 90), deberá ser pecuniariamente resarcido.

El papel "intervencionista" del Estado en muchas de las actividades comerciales (tal y como lo es la importación de vehículos a su territorio) obliga a que dicha entrada esté regida por parámetros mínimos de seguridad, ya que debe haber límites a las mercancías que pueden y no entrar al territorio colombiano. Es así como emerge una nueva posibilidad de la responsabilidad ligada a esta actividad.

La reglamentación acerca de la seguridad de los vehículos en Colombia y en el mundo ha sido un tema de interés, debido al peligro que existe detrás de esta actividad, y más aún en países con ingresos medios, donde en contraste con países de altos y bajos ingresos se produce una tasa elevada de muertes por accidentes ${ }^{1}$.

En vista de lo anterior, resulta necesario formular la siguiente pregunta que será la guía del presente trabajo: ¿es responsable el Estado colombiano por la falla en la vigilancia de las medidas de seguridad en la importación de vehículos? La pregunta se basa en el supuesto de que constitucionalmente la responsabilidad del Estado está amparada y es exigible sin ningún tipo de distinción acerca de cómo se presente, ya que puede ser como un hecho de la Administración. Un típico ejemplo es un accidente de tránsito causado por un vehículo que pertenece a la Administración, o los daños causados por la actuación de la Administración, la omisión que se da cuando se descuida o se omite el cumplimiento de alguna obligación que produce un hecho dañoso, o las operaciones administrativas que se presentan cuando el Estado, en cumplimiento de sus funciones, ocasiona un daño, como en el caso de una construcción.

1 Organización Mundial de la Salud (OMS). INFORME SOBRE LA SITUACIÓN MUNDIAL DE LA SEGURIDAD VIAL 2013. APOYO AL DECENIO DE ACCIÓN. OMS. (2013). Disponible en: https://www.who.int/violence_injury_prevention/road_safety_status/2013/report/es/ 
La responsabilidad del Estado por la falla en la vigilancia de medidas de seguridad en los vehículos que se importan a Colombia, y que transitan en sus vías, se presenta como una omisión en el cumplimiento de las obligaciones constitucionales que posee el Estado de preservar la vida de los colombianos. Los compradores, amparados en la confianza legítima, suponen que los vehículos que compran y que son importados a Colombia cumplen con los estándares de seguridad, también lo hacen aquellos que utilizan servicios de transporte, ya que un gran volumen de los vehículos que transitan en las calles son vehículos de servicio público, como los taxis, en los que los riesgos de colisión son generalmente más altos².

El iter para aterrizar la responsabilidad del Estado en el presente caso debe obedecer a altos estándares de causalidad, ya que se debe considerar que existen intermediarios que podrían compartir la responsabilidad, en atención a que los trámites de legalización y entrada al país serán asumidos por ellos. Sin embargo, esto no deja por fuera el hecho de que el Estado conoce la mercancía que entra al país y que está en la obligación de vigilar y de impedir que aquello que no cumple con los estándares pueda tocar suelo colombiano.

La normativa colombiana al respecto es clara. La Resolución 3752 de 2015 expone que todos los vehículos en Colombia $0 \mathrm{~km}$ o que sean fabricados del 1 de enero de 2017 en adelante deben contar con sistema de frenos ABS, mínimo dos bolsas de aire frontales y apoyacabezas o sistema de retención de cabezas. No obstante esto, existe un vacío que resulta ser potencialmente mortal: no todos los vehículos son 0 km o modelo 2017 en adelante, esto deja por fuera el parque automotor de todo el país que puede no contar con este tipo de accesorios de seguridad ${ }^{3}$.

Dicha omisión es un justificante para analizar la responsabilidad del Estado que regula el tema a través de la cartera de Transporte, con lo que deja en evidencia que ni siquiera con el apoyo de la Policía Nacional con sus medidas de control podrá evitar desenlaces fatales entre los conductores que a diario transitan por las carreteras del país. Esto, sin lugar a dudas, permite un análisis como el que se propone con la pregunta de investigación, la cual deja abierta la puerta a una discusión acerca del riesgo que existe para el Estado no controlar bien sus propios actos, lo que a posteriori le implicará cuestionamientos y posiblemente fallos adversos.

\footnotetext{
2 Lizandro Alfonso Cabrera Suárez. (2019). Responsabilidad del Estado colombiano en accidentes de tránsito por el mal estado de las vías. DIXI 29. Junio 2019. Pág. 1-20. https://doi.org/10.16925/2357-5891.2019.01.02

3 Ministerio de Transporte. Resolución 3752 de 2015. Por la cual se adoptan medidas en materia de seguridad activa y pasiva para uso en vehículos automotores, remolques y semirremolques). Octubre 6 de 2015.
} 
Así las cosas, es oportuna la pregunta de investigación que busca que se suscite un análisis detallado de la normatividad actual frente al tema de seguridad, que dicho sea de paso es pertinente, pero no es suficiente, y en los compromisos constitucionales del Estado está el de proteger a todos los ciudadanos y no solo a aquellos que posean un vehículo $0 \mathrm{~km}$ o modelo 2017 en adelante.

\section{LA RESPONSABILIDAD DEL ESTADO POR LA FALLA EN LA VIGILANCIA DE LAS MEDIDAS DE SEGURIDAD EN LA IMPORTACIÓN DE VEHÍCULOS}

La responsabilidad del Estado representa un tema de incuantificables dimensiones; sabemos dónde inicia, pero no es posible ver con certeza dónde termina, dado que el actuar de este día a día "invade" nuevas esferas de actuación donde ocasionalmente llega a causar daños de naturaleza "antijurídica" y se verá en la obligación de repararlos.

No resulta descabellado incluir dentro de las posibilidades de responsabilidad del Estado su defectuoso actuar en el cuidado de las importaciones a Colombia, pues su falla en la vigilancia de medidas de seguridad de vehículos causa daños a la población que accede a estos productos mediando la buena fe.

Como se vio antes, existen entes del Estado encargados de vigilar, de regular e incluso de recaudar los impuestos que genera la entrada "legal" de los vehículos al territorio nacional. Al ser el papel de los entes tan determinante, debe exigirse que aquel producto que se presenta al consumidor esté dentro de lo que puede considerarse seguro, ya que es sano afirmar que este ha tenido un proceso previo de vigilancia que asegura su calidad.

Las actividades riesgosas como la conducción de un vehículo caen dentro de la órbita de las responsabilidades particulares, porque un accidente de tránsito no es del querer del Estado colombiano y este despliega toda la seguridad vial y demás elementos para evitar su ocurrencia. Ahora bien, dejando de lado este hecho y analizando más a profundidad, debe mirarse que no se cuestiona el hecho de que ocurra un accidente, sino que los resultados de dicho accidente pudieron haberse mitigado o incluso evitado de mediar seriedad en la calidad y la seguridad de los vehículos que se importan. 
Así las cosas, la falla en las medidas de seguridad en las importaciones es el motivo que alienta este análisis, que si bien estira un poco el concepto de falla en el servicio, no deja de ser pertinente y que de aplicarse de forma seria podría evitar daños y perjuicios, aunado a erogaciones multimillonarias del Estado si resultara condenado.

\section{LA FALLA EN EL SERVICIO POR DEFICIENCIAS EN LA VIGILANCIA DE MEDIDAS DE SEGURIDAD EN LA IMPORTACIÓN DE VEHÍCULOS DE TRANSPORTE PÚBLICO}

La falla en el servicio es el régimen subjetivo (con culpa) de la Administración, que predica la responsabilidad del Estado cuando existe una prestación tardía o defectuosa del servicio; es decir, existe ya sea una acción u omisión que traerá consigo la consabida responsabilidad tal y como lo pregona la Constitución ${ }^{4}$.

El Consejo de Estado ha sido enfático en cuanto a la falla en el servicio:

En efecto, la falla del servicio, que es el criterio de imputación principal para establecer la responsabilidad del Estado, tiene como presupuesto el reconocimiento de la existencia de mandatos de abstención — deberes negativos - como de acción — deberes positivos - a cargo del Estado; empero, para que se genere responsabilidad con fundamento en ello es menester acreditar, a título de ejemplo, i) el incumplimiento o deficiente cumplimiento de deberes normativos, ii) la omisión o inactividad de la administración pública, o iii) el desconocimiento de la posición de garante institucional que pueda asumir la administración. ${ }^{5}$

En vista de lo anterior, es necesario adentrarnos en lo que puede considerarse como una posible responsabilidad del Estado por falla en la importación. Se propone que existen varios puntos de vista posibles para ello y que se hace necesario analizarlos detenidamente.

4 Wilson Ruiz Orejuela. RESPonsabiLIDAd del ESTAdo y sus Regímenes. Ecoe Ediciones. (2016).

5 Consejo de Estado. SENTENCIA 32912 DE 2015. (Consejero ponente: Jaime Orlando Santofímio Gamboa; enero 28 de 2015). Disponible en: http://consejodeestado.gov.co/ documentos/sentencias/05001233100020020348701.pdf 
Se ha establecido inicialmente esta responsabilidad en cuanto a los vehículos de servicio público, dado a que hay una razón de acceso a la información porque existe un registro de ello, bien sea en el Ministerio de Transporte o en las secretarías de los municipios o bien en las empresas donde están afiliados. También, valga hacer la claridad, el presente análisis se hará sobre "taxis", es decir, vehículos de transporte urbano de pasajeros. ${ }^{6}$

No se tienen en cuenta vehículos que quizás encajan en el mismo criterio de marcas y modelos que los anteriores, pero de naturaleza particular, por la misma razón de acceso a la información, ya que no necesariamente existe un registro de acceso público de siniestros y mucho menos de personas lesionadas o fallecidas.

El enfoque primario tenderá a establecer que aquellos vehículos de servicio público de taxi tienen errores en su diseño (poco espacio de bodega, falta de airbag dual delantero, falta de frenos ABS o en ocasiones falta de apoyacabezas) que crearán una situación insegura y potencialmente mortal a la hora de un accidente, el cual puede resultar en pretensiones diferentes a las de naturaleza contencioso administrativas como la reparación directa.

Si bien hay un llamado a la cautela frente a esta responsabilidad (que, como es apenas obvio, es tenue y algo teórico por el momento), no deja de encajar en la responsabilidad deprecada por la cláusula general de responsabilidad, que no discrimina si el resultado antijurídico ocurre por acción u omisión ni deja de lado si se da por el actuar de las "autoridades públicas" con todo lo que ello significa.

El Estado colombiano no ha sido negligente frente al tema. Existe la Resolución 3752 de 2015, que establece que todos los vehículos que transiten por las vías nacionales deben (lo cual es imperativo) cumplir con los requisitos de seguridad que establecen las normas para el efecto, establecidos en los artículos 4, 5 y 6 del mencionado acto administrativo (frenos ABS, mínimo dos airbags por vehículo que transporte hasta diez pasajeros y apoyacabezas).

Pero hay una falla en dicho acto que resulta en extremo dañina, y se evidencia en el documento de seguimiento del Ministerio, dirigido a alcaldes municipales, organismos de tránsito y autoridades de tránsito, titulado "Implementación Resolución 3752 de 2015", en el que se hace claridad que "se debe entender que tal y como lo dispone la Resolución 3752 de 2015, no se podrá nacionalizar ningún vehículo a partir del primero de enero de 2017 que no cumpla con lo dispuesto en dicha norma".

6 Taxis de las marcas Hyundai Atos, Chevrolet Spark, Kia Picanto y otros de la variedad de taxi "zapatico", que tienen poco espacio de bodega, no cuentan con airbag dual y quizás no cuentan con frenos ABS ni apoyacabezas. 
El problema no es la loable voluntad del Ministerio de lograr que se proteja la vida de los colombianos; radica en que solo los vehículos con las medidas de seguridad que la norma exige serán viables de nacionalizar, con lo que se dejan olvidados todos aquellos vehículos que antes de esta fecha fueron nacionalizados y no cumplen con estas medidas.

Resulta curioso también que si el objetivo es la protección de los compradores de vehículos, se permita vender las existencias de vehículos que pueden considerarse no aptos para transitar hasta el 30 de abril de 2017, cuestión que se hace en aras de proteger derechos adquiridos, pero sin un verdadero análisis de las posibles consecuencias resultantes.

Entonces bien, está claro que es en extremo cuestionable la medida tomada por el Ministerio de exigir las medidas de seguridad tan solo a los vehículos "nuevos" que circulan por el país, dejando por fuera aquellos que circulan sin cumplir tales medidas que, naturalmente y en aras de la congruencia en la política adoptada, deberían respetarse sin discusión, ya que en este caso podría vislumbrarse una omisión fatal del Estado en cuanto a la no exigencia de adecuación de todo el parque automotor en Colombia que no esté a la par.

La omisión o inactividad del Estado frente a este delicado tema es clara y no puede sumergirse en un velo de irresponsabilidad con el argumento de que es responsabilidad civil en los casos de accidente y que la causa eficiente del accidente no es responsabilidad del Estado. Es claro que la ocurrencia del accidente no lo es, pero no debe perderse de vista que sí lo es la omisión en la política para vehículos que circulan y que no cuentan con medidas de protección, y argumentar lo contrario resulta falaz.

Es indispensable, de igual manera, establecer que el nexo de causalidad no se diluye en el presente entendido, dado que puede, entre los tres elementos requeridos para atribuir responsabilidad al Estado (daño, hecho generador y nexo de causalidad), configurarse en los accidentes de tránsito mencionados. Una cosa es el accidente en sí y otra son los resultados a causa de la falla en las medidas de seguridad, que en toda justicia deben ser iguales para todos los asociados y no solo para aquellos que compran vehículos de 2017 en adelante.

Frente al nexo, Patiño ${ }^{7}$ establece:

7 Héctor E. Patiño. (2011). Las causales exonerativas de la responsabilidad extracontractual. ¿Por qué y cómo impiden la declaratoria de responsabilidad?: aproximación a la jurisprudencia del Consejo de Estado. REVISTA DE DERECHO PRIVADO 20. Enerojunio 2011 . Pág. 371-398. https://revistas.uexternado.edu.co/index.php/derpri/article/ view/2898 
El nexo causal se entiende como la relación necesaria y eficiente entre el hecho generador del daño y el daño probado. La jurisprudencia y la doctrina indican que para poder atribuir un resultado a una persona y declararla responsable como consecuencia de su acción u omisión, es indispensable definir si aquel aparece ligado a esta por una relación de causa-efecto. Si no es posible encontrar esa relación mencionada, no tendrá sentido alguno continuar el juicio de responsabilidad.

La relación causa-efecto, para el presente caso, se delimita claramente en la causalidad del Estado en una situación mucho más insegura de la que debe legalmente soportar una persona. Esto se materializa en la persona que conduzca un vehículo modelo previo a 2017, quien de exigírsele cumplir con la norma podría evitar, en caso de siniestro, lesiones graves y permanentes o incluso la muerte, y no solo a ella sino también a sus pasajeros.

De acuerdo con Gil8, el principio de seguridad es uno de los pilares a tener en cuenta dentro de las actividades de tránsito y podría, por analogía, aplicarse a situaciones como la que se está analizando. La Ley 336 de 1996 en su artículo 2 promociona este principio así: "La seguridad, especialmente la relacionada con la protección de los usuarios, constituye prioridad esencial en la actividad del Sector y del Sistema de Transporte"9.

Es así como la responsabilidad del Estado en el caso de la falta de vigilancia genera una especial necesidad de revisión, ya que la falla en el servicio de vigilancia y control aduanero sobre vehículos no aparece en el momento en que se profirió la norma que exige las medidas de seguridad mencionadas, ni opera ipso iure, sino que aparecerá cuando se materialice el daño como tal, que sería a efectos de esta discusión el momento mismo del accidente que genera los daños antijurídicos.

Queda en evidencia el hecho de que no es posible argumentar, tampoco, la ausencia de responsabilidad por alguno de los factores que eximen al Estado de la culpabilidad, que para la responsabilidad extracontractual son: la fuerza mayor, el hecho de un tercero y la culpa de la víctima, los cuales deben ser analizados a profundidad por parte de un operador jurídico antes de proferirse un fallo de responsabilidad.

8 Enrique Gil Botero. ResPonsabilidad EXTRAContractual Del EStado. Temis. (2013).

9 Congreso de la República. Ley 336 de 1996. Por la cual se adopta el Estatuto Nacional de Transporte. Diciembre 20 de 1996. Do 42.948. 
La fuerza mayor, que en el caso colombiano no se ha desligado del caso fortuito, se viene tratando de forma insistente en la jurisprudencia en busca de la diferenciación entre ellos. Así, la Corte Constitucional ha sentado que:

La jurisprudencia del Consejo de Estado ha diferenciado la fuerza mayor del caso fortuito, en tanto la fuerza mayor es causa extraña y externa al hecho demandado; se trata de un hecho conocido, irresistible e imprevisible, que es ajeno y exterior a la actividad o al servicio que causó el daño. El caso fortuito, por el contrario, proviene de la estructura de la actividad de aquel, y puede ser desconocido, permanecer oculto, y en la forma que ha sido definido, no constituye una verdadera causa extraña, con virtualidad para suprimir la imputabilidad del daño. ${ }^{10}$

El hecho de un tercero y la culpa de la víctima no pueden argüirse como causales de exoneración de responsabilidad, dado que no se está cuestionando la causación del accidente de tránsito como tal, sino que se cuestionan los daños sufridos por quienes se desplazan en el vehículo y que los sufrieron en mayor medida gracias a la negligencia del Estado en su deber de protección, consagrado en el artículo 2 superior: "Las autoridades de la República están instituidas para proteger a todas las personas residentes en Colombia, en su vida, honra, bienes, creencias, y demás derechos y libertades, y para asegurar el cumplimiento de los deberes sociales del Estado y de los particulares".

Resulta, pues, irrelevante cuestionar si el accidente es o no causado por la voluntad de quien sufre daños, o si para la realización del daño hubo un tercero que participa como cocausador. Tal y como se expresó, importa es la situación de inseguridad que se propicia por la falla del Estado en prevenir de forma efectiva que circulen vehículos que no están a la altura de los estándares internacionales de seguridad vehicular.

La normatividad colombiana de seguridad vehicular invoca el anexo 13 del Reglamento 13 de la Comisión Económica de las Naciones Unidas para Europa, en el que se hacen los análisis pertinentes en seguridad vehicular que se emulan para el territorio nacional, iniciando con los mecanismos de frenado y el tema de la homologación, es decir, el salvoconducto de entrada de un vehículo por cumplir con las normas de un país a donde se busca su entrada. El mencionado documento expone que:

10 Corte Constitucional de Colombia. SENTENCIA SU-449 DE 2016. (Magistrado ponente: Jorge Ignacio Pretelt Chaljub; agosto 22 de 2016). 
Sistema de frenado de servicio: El sistema de frenado de servicio deberá permitir controlar el movimiento del vehículo y pararlo de forma segura, rápida y eficaz, cualesquiera que sean la velocidad, la carga o la pendiente ascendente o descendente en la que se encuentre. Su acción deberá ser regulable. El conductor deberá poder frenar de esta manera desde su asiento sin retirar las manos del mando de dirección."

Visto lo anterior, es en extremo deseable que estas características de equipo de freno sean universales en el parque automotor de Colombia, donde los vehículos que circulan no necesariamente cumplen con la posesión de este mecanismo, lo que los hace inseguros a la hora del frenado.

El Reglamento 94 de la Comisión Económica para Europa de las Naciones Unidas regula lo atinente a la protección de los ocupantes en caso de colisión frontal, cuestión en extremo delicada, dado que la necesidad de airbag dual tal y como lo dispone la normativa colombiana de seguridad (tomada de la norma europea mencionada) debe ser un elemento indispensable en todos los vehículos circulantes.

La no tenencia de bolsas de aire (mínimo dos) resulta innecesariamente insegura para los conductores de vehículos de modelos previos a 2017, ya que la norma no lo exige para ellos. Aun así, y viendo cómo constitucionalmente uno de los objetivos primordiales del Estado es la protección de la "vida, honra y bienes", es muy importante una política de implementación global de esta medida dado que las colisiones frontales de carros sin bolsas de aire pueden probar ser fatales.

Se hace necesario, aparte del nexo de causalidad, el análisis de la responsabilidad en concreto y del modelo de imputación atribuible al Estado, así como entrar a revisar la teoría del riesgo que busca establecer responsabilidades, más aun considerando que la actividad de conducir un vehículo es una que, sin importar la diligencia que se aplique, puede resultar en accidentes, lesiones y posiblemente muertes.

11 Comisión Económica de las Naciones Unidas para Europa. Reglamento $\mathrm{n}^{\circ} 13$ de la Comisión Económica para Europa (CEPE) de las Naciones Unidas. Disposiciones uniformes sobre la homologación de vehículos de las categorías $\mathrm{M}, \mathrm{N}$ y $\mathrm{O}$ con relación al frenado [2016/194]. Octubre 8 de 2015. Disponible en: https://eur-lex.europa.eu/legal-content/ES/TXT/?uri=CELEX\%3A42016X0218\%2801\%29 


\section{LA TEORÍA DEL RIESGO COMO POSIBLE FACTOR DENTRO DE LA RESPONSABILIDAD DEL ESTADO POR LA FALLA EN LA VIGILANCIA DE LAS MEDIDAS DE SEGURIDAD EN LA IMPORTACIÓN DE VEHÍCULOS}

La teoría del riesgo surge como un modelo especial que tiene en cuenta la posibilidad de que los perjuicios ocasionados por actividades de naturaleza "riesgosa" sean responsabilidad de quien pone en riesgo o provee el mayor riesgo a la persona que sufre el daño por la ejecución de dicha actividad. En resumidas cuentas, atribuye responsabilidad a quien puso en riesgo a la persona "damnificada":

La teoría del riesgo se caracteriza por la facilidad para identificar no solamente al autor físico de daño, sino a una serie de personas que giran en tomo al riesgo creado y se beneficia o lucra con la creación de ese riesgo. Lo anterior permite que desde el punto de vista procesal no quepa la pregunta, ¿quién era el guardián de la actividad o cosa riesgosa causante del daño para saber quién es el sujeto pasivo de la pretensión procesal? En la responsabilidad por riesgo no se pregunta quién causó físicamente el daño, sino quién o quiénes crearon el riesgo que se concretó en un daño sin tener que recurrir al intricado concepto francés de guardián utilizado en Colombia para las actividades peligrosas.?2

Resulta palpable, entonces, cómo una actividad netamente riesgosa como la conducción de vehículos automotores puede, en el entendido mencionado, resultar en un cuestionamiento de "quién o quiénes" son responsables por los daños causados; es decir, dado el infausto suceso de un accidente vehicular, con esta teoría se podría no solo cuestionar directamente quién causo el accidente y bajo qué premisas, ya que esto resulta irrelevante para la discusión actual, sino también cómo se aumentó de forma "antijurídica" el riesgo para quienes resultaron afectados.

Naturalmente, este cuestionamiento a profundidad del riesgo llegará a las puertas del Estado colombiano que permitió, con su actuar descuidado y negligente, el aumento injustificado del riesgo que normalmente debería asumir una persona; así

12 Saúl Uribe García. (2017). La responsabilidad por riesgo. RATIO JURIS 1. Julio-diciembre 2017. Pág. 29-50. Disponible en: https://publicaciones.unaula.edu.co/index.php/ratiojuris/article/view/297 
las cosas, con un negligente cuidado en la nacionalización de un vehículo que se sabe que es inseguro, el Estado debe asumir las consecuencias.

El Consejo de Estado ha aplicado de forma consistente la teoría del riesgo bajo el título de "riesgo excepcional", pero con el entendido de que este régimen está encuadrado dentro del considerado "objetivo", es decir, sin culpa, ya que la sola puesta en riesgo a los particulares por parte del Estado con su actuar supone responsabilidad. El uso de armas y la conducción de vehículos son casos claros que entrañan un riesgo considerable incluso bajo las medidas de cuidado más superlativas.

Entonces, la naturaleza de la aplicación del riesgo excepcional para el presente caso desharía la posibilidad de que pueda tratarse de una falla en el servicio; tal y como se dijo, la falla pertenece al régimen de lo subjetivo. En el presente análisis, se propugna una aplicación del entendido del riesgo como una situación posiblemente determinante dentro de la responsabilidad, dado que sin esta actuación del Estado, que desde luego está cargada de culpa, carecería de fuerza el argumento de que la situación que propicia el Estado al permitir circular un vehículo "no seguro" no lo responsabiliza, ya que la situación como tal no la causa el Estado mismo, sino el particular (ya sea por acción u omisión) en el evento de un accidente.

La discusión del riesgo no se centra en la responsabilidad o no en un accidente, se centra en que los defectos del vehículo son los causantes de los daños que se acrecentaron con el actuar culpable del Estado, cuyos sus estándares de seguridad y entes encargados de vigilar las importaciones debieron, a toda costa, evitar que se nacionalizara, o para el caso colombiano, que con la normativa actual siguiera circulando. Esto último supone no que se ignora la reglamentación actual, sino que en congruencia con ella debería evitarse que tales vehículos sigan circulando para ajustarse a las medidas actuales, o que actuando bajo los entendidos constitucionales de protección de la vida de los asociados se evite que productos no seguros les causen daño.

Frente al riesgo, el Consejo de Estado cita a Larenz ${ }^{13}$ argumentando lo siguiente:

Sin duda, es un aporte que se representa en lo considerado por Larenz según el cual había necesidad de "excluir del concepto de acción sus efectos imprevisibles, por entender que estos no pueden considerarse obra del autor de la acción, sino obra del azar". Con lo anterior, se logra superar, definitivamente, en el juicio de responsabilidad, la aplicación tanto de la teoría de la equivalencia de condiciones, como de la causalidad CHNUNG. Scholl. (1927). 
adecuada, ofreciéndose como un correctivo de la causalidad, donde será determinante la magnitud del riesgo y su carácter permisible o no. Es más, se sostiene doctrinalmente "que la responsabilidad objetiva puede llegar a tener, en algunos casos, mayor eficacia preventiva que la responsabilidad por culpa. ¿Por qué? Porque la responsabilidad objetiva, aunque no altere la diligencia adoptada en el ejercicio de la actividad (no afecte a la calidad de la actividad), sí incide en el nivel de la actividad (incide en la cantidad de actividad) del sujeto productor de daños, estimulando un menor volumen de actividad (el nivel óptimo) y, con ello, la causación de un número menor de daños. ${ }^{14}$

Resulta palpable que la diferencia entre el modelo objetivo y el modelo subjetivo es el elemento de la culpa, pero no puede descartarse la importancia que presenta el riesgo para el análisis de la responsabilidad del Estado cuando se trata de la falla de las medidas de vigilancia en la importación, ya que esa misma falla ocurre por el riesgo sobreviniente y permitido por el Estado en cuanto a vehículos que no cumplen con medidas en extremo necesarias para la salud y vida de los asociados que conducen vehículos.

Es así como el riesgo creado por el Estado por permitir que vehículos con pobres medidas de seguridad ingresen al territorio colombiano y, además, por no exigir que las medidas que él mismo exige sean de universal aplicación a todos los vehículos, es un riesgo que no puede desconocerse y que necesariamente debe generar la responsabilidad que se depreca, ya que hacerlo es alejar la reparación integral que la normativa ha exigido en la Ley 446 de $1998^{15}$.

\section{LA VÍA PROCESAL DE LA REPARACIÓN DIRECTA Y LA NECESIDAD DE REPARACIÓN}

El Código de Procedimiento Administrativo y de lo Contencioso Administrativo (CPA$\mathrm{CA}$ ) ha establecido que la vía procesal o "medio de control" (nombre inoficioso en los

14 Consejo de Estado, Sección Tercera. Expediente 20220 de 2011. Disponible en: https:// www.redjurista.com/Documents/consejo_de_estado,_seccion_tercera_e._no._20220_ de_2011.aspx\#/

15 Artículo 16. valoración de daños. Dentro de cualquier proceso que se surta ante la Administración de Justicia, la valoración de daños irrogados a las personas y a las cosas, atenderá los principios de reparación integral y equidad y observará los criterios técnicos actuariales. 
términos de Henao y Ospina ${ }^{16}$ ) de la reparación directa es en efecto el medio idóneo establecido en Colombia para exigir la reparación de los daños antijurídicos sufridos a manos del Estado. El artículo 140 del mencionado CPACA con claridad expone las razones por las que procede y cuál es la naturaleza del medio de control, que es indemnizatoria. ${ }^{17}$

Es menester aclarar que el daño antijurídico es aquel que el afectado no está en obligación de soportar, ya que en el ordenamiento jurídico colombiano existen cargas públicas de necesaria y obligatoria aceptación. A modo de ejemplo, tenemos las obras públicas, los impuestos y en ocasiones la prestación de servicios al Estado, como el de conscripción militar, que deben ser aceptados y no generan per se una reparación a menos que esta llegue a vulnerar derechos más allá de lo soportable. Frente a lo anterior se ha pronunciado la Corte Constitucional varias veces.

En la Sentencia C-333 de 1996, con ponencia del magistrado Alejandro Martínez Caballero, resaltó la armonía existente entre el régimen de responsabilidad patrimonial del Estado consagrado en el artículo 90 de la Carta y el Estado Social de Derecho:

Desde el punto de vista sistemático, la Corte considera que esta acepción del daño antijurídico como fundamento del deber de reparación del Estado armoniza plenamente con los principios y valores propios del Estado Social de Derecho (CP art. $\left.7^{\circ}\right)$, pues al propio Estado corresponde la salvaguarda de los derechos y libertades de los particulares frente a la actividad de la administración. Así, la responsabilidad patrimonial del Estado se presenta entonces como un mecanismo de protección de los administrados frente al aumento de la actividad del poder público, el cual puede ocasionar daños, que son resultado normal y legítimo de la

16 Juan Carlos Henao y Andrés Fernando Ospina Garzón (Eds.). LA RESPONSABILIDAD EXTRACONTRACTUAL DEL ESTADO: ¿QUÉ?, ¿POR QUÉ?, ¿HASTA DÓNDE? XVI JORNADAS INTERNACIONALES DE DERECHO ADMINISTRATIVO. Editorial Universidad Externado. (2015).

17 Artículo 140. "Reparación directa. En los términos del artículo 90 de la Constitución Política, la persona interesada podrá demandar directamente la reparación del daño antijurídico producido por la acción u omisión de los agentes del Estado. De conformidad con el inciso anterior, el Estado responderá, entre otras, cuando la causa del daño sea un hecho, una omisión, una operación administrativa o la ocupación temporal o permanente del inmueble por causa de trabajos públicos o por cualquiera otra causa imputable a una entidad pública o a un particular que haya obrado siguiendo una expresa instrucción de la misma. Las entidades públicas deberán promover la misma pretensión cuando resulten perjudicadas por la actuación de un particular o de otra entidad pública. En todos los casos en los que en la causación del daño estén involucrados particulares y entidades públicas, en la sentencia se determinará la proporción por la cual debe responder cada una de ellas, teniendo en cuenta la influencia causal del hecho o la omisión en la ocurrencia del daño". 
propia actividad pública, al margen de cualquier conducta culposa o ilícita de las autoridades, por lo cual se requiere una mayor garantía jurídica a la órbita patrimonial de los particulares [...]..$^{18}$

Queda en evidencia que el daño antijurídico que pregona la Constitución ha tenido su desarrollo y su explicación desde la jurisprudencia y la doctrina, tal y como lo explica Navia ${ }^{19}$. La connotada influencia española en la cláusula general de responsabilidad del Estado colombiano trajo consigo este concepto que requirió un trabajo de explicación adicional, ya que la carta misma no lo hacía.

A pesar de lo mencionado, que es la base constitucional actual del citado medio de control, no siempre la responsabilidad del Estado tuvo dicha base, tomando como fundamento artículos de la centenaria Constitución de $1886^{20}$ y del articulado del aún vigente Código Civil en cuanto a la responsabilidad de naturaleza extracontractual21; no debe tampoco olvidarse el ya derogado Decreto 01 de 1984 o Código de lo Contencioso Administrativo.

En la actualidad, no cabe duda de que el procedimiento por excelencia será la reparación directa y que ante la posible responsabilidad del Estado por la falla en la vigilancia de las medidas de seguridad que le son exigibles en materia de importación de vehículos, deberá, sin hesitación alguna, acudirse a este con los procedimientos que establece la normativa actual en materia contencioso administrativa, como lo son la conciliación previa. A mi entender, este es un requisito baladí, ya que la ocurrencia de los acuerdos es poco probable y no se le ha dado la seriedad necesaria a este mecanismo alternativo de solución de conflictos; deberá cumplirse además con los requisitos de una demanda y las ritualidades que se observan en audiencia que trae la Ley 1437 de 2011.

La necesidad de reparación, en su más amplio sentido, es una de las razones por las cuales se incoa el medio de control de reparación directa, dado que no solo se pretende la reparación dineraria que sería más bien una indemnización, se debe

18 Corte Constitucional de Colombia. SENTENCIA C-333 DE 1996. (Magistrado ponente: Alejandro Martínez Caballero; agosto 1 de 1996).

19 Felipe Navia Arroyo. (2000). Responsabilidad extracontractual del Estado a la luz del artículo 90 de la Constitución Política. REVISTA DE DERECHO PRIVADO 6. Julio-diciembre 2000. Disponible en: https://revistas.uexternado.edu.co/index.php/derpri/article/ view/659

20 Entre otros artículos véase el artículo 19 de la mencionada Carta, según el cual las autoridades estaban establecidas para proteger a todos los residentes en Colombia en su vida, honra y bienes.

21 Artículo 2341. "El que ha cometido un delito o culpa, que ha inferido daño a otro, es obligado a la indemnización, sin perjuicio de la pena principal que la ley imponga por la culpa o el delito cometido". 
también, en el más amplio de los entendidos, buscar que se repare el daño que se causó, es decir, volver las cosas a su estado anterior a la lesión, una verdadera reparación in natura tal y como lo señalan Henao y Ospina ${ }^{22}$.

Es así que no solo podrá exigirse las indemnizaciones a los perjuicios de naturaleza material, es decir, lucro cesante y daño emergente (estas suelen aplicar al contexto de las víctimas del conflicto armado), sino también a los perjuicios inmateriales como lo son el daño moral y el daño a la salud. Eventualmente, y de poderse probar en este caso (que considero poco probable), podrá exigirse la indemnización a la afectación a bienes constitucional y convencionalmente protegidos, con lo que se permitiría tener acceso a una amplia gama de posibilidades que resultarían útiles en caso de un posible litigio.

Pero si se habla de reparación in natura, el Estado colombiano debe también estar abierto a la posibilidad de reconocer medidas de satisfacción como el reconocimiento de la culpa y la solicitud de perdón, así como medidas de rehabilitación como acompañamiento psicosocial o rehabilitación física, que no dejan de ser válidas para el caso, ya que el daño toma numerosas e insospechadas formas. De considerarse pertinente, el juez administrativo podrá ordenar que estas rehabilitaciones se tengan como medida de reparación in integrum de los daños que acaecen por responsabilidad del Estado, como lo es un posible accidente de tránsito.

Está claro que estas últimas medidas mencionadas no encajan necesariamente dentro de las medidas de reparación más comunes. Aun así, no puede dejarse por fuera que el querer de una sociedad justa es que por todos los daños que reciba una persona, y más aún, una que reciba un daño del Estado mismo, se le deberán otorgar todas las ventajas y garantías para recibir una indemnización justa y una verdadera reparación en toda la amplitud de la palabra

Deben recordarse los compromisos adquiridos por el Estado colombiano en materia de justicia, que obligan a la reparación contenida en la Resolución 60/147 de las Naciones Unidas, que si bien trata un tema de derechos humanos, no deja de lado el hecho de que un compromiso en la justicia colombiana debe ser obtener este tipo de reparación en los términos que el mencionado documento pregona: "reparación adecuada, efectiva y rápida del daño sufrido"

A través de la reparación directa contemplada en el CPACA, se lograría la "reparación" del daño sufrido. Es comprensible la reticencia que generaría entre los jueces eventualmente avocados a conocer este tipo de pretensiones la posibilidad de utilizar un documento encaminado a reparar temas de violaciones a derechos humanos, pero en el sentido más amplio de la justicia y su más estricta aplicación debería aunque sea

22 Henao y Ospina, supra, nota 17. 
considerarse como una posibilidad garantista y fiel al "control de convencionalidad que les es exigible a los jueces administrativos en Colombia". ${ }^{23}$

\section{La necesidad de cambios en el parque automotor colombiano}

De acuerdo con BBVA ${ }^{24}$, el parque automotor de Colombia es de trece millones de vehículos, dividido en 7,1 millones de motocicletas y 5,9 millones de automotores, lo que muestra una considerable cantidad de vehículos circulando en las carreteras colombianas. Ahora bien, para responder a la pregunta por las edades de tales vehículos, la Asociación Colombiana de Vehículos Automotores (Andemos) presenta la figura 1:

\section{Parque Automotor por Grupo de Edades}

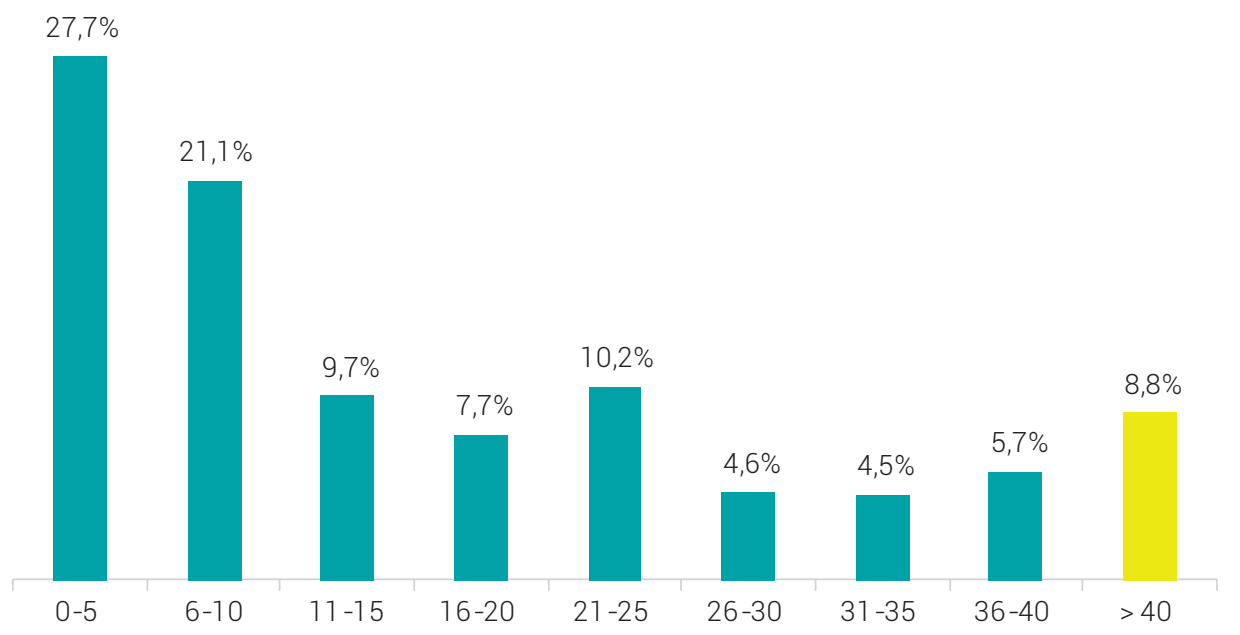

Figura 1. Edad del parque automotor colombiano Fuente: Andemos $^{25}$.

La gráfica anterior refleja una preocupación bastante grande: que los vehículos que circulan por Colombia son, a falta de una mejor palabra, "viejos". Esta afirmación

23 Corte Interamericana de Derechos Humanos. CUADERNILLO DE JURISPRUDENCIA DE LA CORTE INTERAMERICANA DE DERECHOS HUMANOS N. ${ }^{\circ}$ : CONTROL DE CONVENCIONALIDAD. Corte IDH. (2019). Disponible en: https://biblioteca.corteidh.or.cr/documento/68698

24 BBVA Research. Situación automotriz 2018 Colombia. 2018. Disponible en: https:// www.bbvaresearch.com/wp-content/uploads/2018/03/SituacionAutomotriz2018.pdf

25 Asociación Colombiana de Vehículos Automotores (Andemos). Presentación parque automotor Colombia. 2016. Disponible en: https://www.andemos.org/index. php/2017/01/10/presentacion-sector-automotor-colombia/ 
se hace en el entendido de que en 2016 ya se contaba con un parque automotor que ya era considerablemente viejo y, más aún, que no tiene las "nuevas" medidas de seguridad que ha propuesto el Ministerio, con lo cual se concluye que, en su gran mayoría, los vehículos que transitan en el país son inseguros.

Es necesaria una medida de choque para esta peligrosa realidad, una medida de cambio total para todos los vehículos anteriores al año 2017. Está claro que esto no podría lograrse de golpe y que se requeriría un periodo considerable de tiempo para hacer la transición en los vehículos más antiguos. Es escandaloso que aproximadamente 8,8 \% de los vehículos circulantes tienen más de 40 años de antigüedad, es decir, 470000 automotores.

El Estado no podría hacer esta exigencia sin algún tipo de contraprestación que solvente, de alguna manera, las pérdidas económicas que representaría para los colombianos deshacerse de sus vehículos. Quizás podrían ofrecerse incentivos por la chatarrización y subsidios para la adquisición de vehículos nuevos, lo que sería una especie de motivación para ir sacando de circulación las existencias que no cumplan con los requisitos establecidos.

La chatarrización de vehículos de carga para Colombia es una tarea fundamental y un requisito para su entrada en la Organización para la Cooperación y el Desarrollo Económicos (Ocde), situación mediante la cual se propone un programa en lo atinente a vehículos de carga, que son la espina dorsal del sistema comercial colombiano, ya que en sus carreteras estos circulan las 24 horas del día. Quizás podría homologarse esta estrategia para los vehículos livianos, con la propuesta de una política pública muy popular y que reduciría las fatalidades relacionadas con accidentes ${ }^{26}$.

De pronto es llevar algo lejos el presente tema proponer algo tan ambicioso y que pudiera desviarse del tema de la responsabilidad del Estado, dado que parecería diluirse demasiado el nexo de causalidad entre el daño y su causación a manos del Estado en vehículos que ya tienen muchos años circulando, más aún si estos no fueron importados como es el caso sub examine, pero no sobra prever los riesgos y proteger la vida de los colombianos.

\section{La insuficiente acción administrativa y de policía frente a la seguridad vehicular}

Las autoridades son insuficientes para atender y controlar un fenómeno de proporciones tan grandes como el que se ha mostrado. Los millones de vehículos circulantes

26 Congreso de la República. Ley 769 de 2002. Por la cual se expide el Código Nacional de Tránsito Terrestre y se dictan otras disposiciones. Septiembre 13 de 2002. Do 44.932. 
en las vías de Colombia son, con toda evidencia, inseguros para sus ocupantes y para los peatones, dado que las medidas de seguridad que ofrecen son pobres y no están a la altura de los estándares actuales. El Código Nacional de Tránsito establece:

Todos los vehículos que circulen por el territorio nacional deben someterse a las normas que sobre tránsito terrestre determine este Código. Estos deben cumplir con los requisitos generales y las condiciones mecánicas y técnicas que propendan a la seguridad, la higiene y comodidad dentro de los reglamentos correspondientes sobre peso y dimensiones. ${ }^{27}$

Resultaría en extremo difícil, por no decir imposible, que se inmovilizara a la gran mayoría de los millones de vehículos en Colombia por no cumplir con todos los requisitos de seguridad, ni qué decir de los vehículos que se dedican a funciones comerciales o de transporte de mercancía, pues obligar su inmovilización posiblemente ocasionaría un daño antijurídico que tan solo aumentaría lo conflictivo de este tema. Es por eso que la Administración debería adoptar medidas escalonadas de obediencia con miras a este cambio tan necesario.

De acuerdo con datos de la Agencia Nacional de Seguridad Vial (ANSV) ${ }^{28}$, de enero a agosto de 2019 hubo 4213 muertos en accidentes de tránsito, con la disminución de solo diecinueve casos con respecto al mismo periodo del año anterior. Esto evidencia que una de las principales causas de muerte en Colombia son los accidentes de tránsito; de la mencionada cifra el 7,67 \% corresponde a vehículos individuales.

Así las cosas, queda en evidencia que las autoridades no cuentan con suficiente capacidad para retener o multar a los vehículos que se consideran inseguros y que circulan libremente por el territorio. Es posible que esto ocurra por desconocimiento de las medidas que se han tomado en torno a esta situación o porque simplemente la aplicación de normas con rango de ley como el Código Nacional de Tránsito resultan más imperativas que la Resolución 3752 de 2015.

\section{CONCLUSIONES}

- Hay una evidente falta de controles a las medidas de seguridad en los vehículos, lo cual ocasiona un elevado número de accidentes de tránsito

27 Idem.

28 Agencia Nacional de Seguridad Vial (ANSv). Boletín estadístico Colombia: fallecidos y lesionados serie nacional. 2019. Disponible en: https://ansv.gov.co/es/observatorio/ publicaciones/boletin-estadistico-colombia-fallecidos-y-lesionados-serie-nacional-0 
con desenlaces fatales que en gran medida podrían ser evitados con una política seria de actualización y chatarrización de vehículos que no puedan ser "homologados" a las condiciones actuales de seguridad que trae la Resolución 3752 de 2015.

- La responsabilidad del Estado se ve comprometida con aquellos vehículos que circulan sin las medidas de seguridad establecidas en la Resolución 3752 de 2015, dado que si bien esta norma no es de carácter retroactivo, sí evidencia que el Estado no está en la capacidad de proteger a todos los colombianos en su vida, honra y bienes, y que es en razón a esto que la falla en las medidas de seguridad en las importaciones ha permitido que vehículos inseguros como taxis tipo sin bodega y sin airbag dual, frenos ABS ni apoyacabezas circulen por las ciudades sin ningún tipo de control a su seguridad.

- El anticuado parque automotor de Colombia debe ser actualizado de manera escalonada. Como medida de choque a esta difícil y quizás impopular orden, se proponen alivios de tipo tributario o quizás de naturaleza económica para facilitar la obtención de vehículos nuevos o que al menos cumplan con la normatividad en seguridad actual.

- No puede desconocerse el esfuerzo del Estado en la búsqueda de la seguridad mediante la implementación de la Resolución 3752 de 2015, que busca mejorar las condiciones de seguridad vehicular. Pero aun con esto no puede obviarse el hecho de que esta medida llega a destiempo, ya que el parque automotor colombiano (de aproximadamente seis millones de vehículos) no cuenta en su totalidad con dicha seguridad, haciéndolo vulnerable e inseguro. El Estado no puede desconocer esto y es por su carencia en esta materia que posiblemente se compromete su responsabilidad.

\section{REFERENCIAS}

Agencia Nacional de Seguridad Vial (ANSV). Boletín estadístico Colombia: fallecidos y lesionados serie nacional. 2019. Disponible en: https:/ansv.gov.co/es/observatorio/publicaciones/ boletin-estadistico-colombia-fallecidos-y-lesionados-serie-nacional-0

Asociación Colombiana de Vehículos Automotores (Andemos). Presentación parque automotor Colombia. 2016. Disponible en: https://www.andemos.org/index.php/2017/01/10/ presentacion-sector-automotor-colombia/ 
BBVA Research. Situación automotriz 2018 Colombia. 2018. Disponible en: https://www.bbvaresearch.com/wp-content/uploads/2018/03/SituacionAutomotriz2018.pdf

Comisión Económica de las Naciones Unidas para Europa. Reglamento n 13 de la Comisión Económica para Europa (CEPE) de las Naciones Unidas. Disposiciones uniformes sobre la homologación de vehículos de las categorías M, N y O con relación al frenado [2016/194]. Octubre8de2015. Disponibleen:https://eur-lex.europa.eu/legal-content/ES/TXT/?uri=CELEX \%3A42016X0218\%2801\%29

Congreso de la República. Ley 336 de 1996. Por la cual se adopta el Estatuto Nacional de Transporte. Diciembre 20 de 1996. DO 42.948.

Congreso de la República. Ley 769 de 2002. Por la cual se expide el Código Nacional de Tránsito Terrestre y se dictan otras disposiciones. Septiembre 13 de 2002. DO 44.932.

Consejo de Estado, Sección Tercera. Expediente 20220 de 2011. Disponible en: https://www.redjurista.com/Documents/consejo_de_estado,_seccion_tercera_e._no._20220_de_2011.aspx\#/

Consejo de Estado. SentenCIA 32912 DE 2015. (Consejero ponente: Jaime Orlando Santofímio Gamboa; enero 28 de 2015). Disponible en: http://consejodeestado.gov.co/documentos/ sentencias/05001233100020020348701.pdf

Corte Constitucional de Colombia. SEnTENCIA C-333 DE 1996. (Magistrado ponente: Alejandro Martínez Caballero; agosto 1 de 1996).

Corte Constitucional de Colombia. SENTENCIA SU-449 DE 2016. (Magistrado ponente: Jorge Ignacio Pretelt Chaljub; agosto 22 de 2016).

Corte Interamericana de Derechos Humanos. CuAdernillo de JuRISPRUdencia de LA CORTE Interamericana de Derechos Humanos N. ${ }^{\circ}$ 7: Control de Convencionalidad. Corte idh. (2019). Disponible en: https://biblioteca.corteidh.or.cr/documento/68698

Enrique Gil Botero. ResponsabILIDAD EXtracontractual del Estado. Temis. (2013).

Felipe Navia Arroyo. (2000). Responsabilidad extracontractual del Estado a la luz del artículo 90 de la Constitución Política. Revista DE DERECHo PrIVAdo 6. Julio-diciembre 2000. Disponible en: https://revistas.uexternado.edu.co/index.php/derpri/article/view/659

Héctor E. Patiño. (2011). Las causales exonerativas de la responsabilidad extracontractual. ¿Por qué y cómo impiden la declaratoria de responsabilidad?: aproximación a la jurisprudencia del 
Consejo de Estado. Revista de Derecho Privado 20. Enero-junio 2011. Pág. 371-398. https:// revistas.uexternado.edu.co/index.php/derpri/article/view/2898

Juan Carlos Henao y Andrés Fernando Ospina Garzón (Eds.). LA RESPONSABILIDAD EXTRACONTRACTUAL DEL ESTADO: ¿QUÉ?, ¿POR QUÉ?, ¿HASTA DÓNDE? XVI JORNADAS INTERNACIONALES DE DERECHO AdmInISTRATIVO. Editorial Universidad Externado. (2015).


(1927).

Lizandro Alfonso Cabrera Suárez. (2019). Responsabilidad del Estado colombiano en accidentes de tránsito por el mal estado de las vías. DIXI 29. Junio 2019. Pág. 1-20. https://doi. org/10.16925/2357-5891.2019.01.02

Ministerio de Transporte. Resolución 3752 de 2015. Por la cual se adoptan medidas en materia de seguridad activa y pasiva para uso en vehículos automotores, remolques y semirremolques). Octubre 6 de 2015.

Organización Mundial de la Salud (OMS). INFORME SOBRE LA SITUACIÓN MUNDIAL DE LA SEGURIDAD VIAL 2013. APOYO AL DECENIO DE ACCIÓN. OMS. (2013). Disponible en: https://www.who.int/ violence_injury_prevention/road_safety_status/2013/report/es/

Saúl Uribe García. (2017). La responsabilidad por riesgo. RATIO JURIS 1. Julio-diciembre 2017. Pág. 29-50. Disponible en: https://publicaciones.unaula.edu.co/index.php/ratiojuris/article/ view/297

Wilson Ruiz Orejuela. ReSPonSABILIdAd DEL ESTAdo y sus Regímenes. Ecoe Ediciones. (2016). 